\title{
Identification of Various Chemical Compounds in Methanolic and Chloroform Crude Extracts of Groundnut Seed Coat by GC-MS
}

\author{
C. Sivananth ${ }^{1} *$, S. Amutha ${ }^{1}$, G. Hemalatha ${ }^{1}$, M.L. Mini ${ }^{2}$ and G. Karthikeyan ${ }^{3}$ \\ ${ }^{1}$ Department of Food Science and Nutrition, HSC\&RI, ${ }^{2}$ Department of Biotechnology, AC\&RI, \\ ${ }^{3}$ Department of Plant Pathology, Tamil Nadu Agricultural University, \\ Madurai District, Tamil Nadu, India \\ *Corresponding author:
}

\begin{tabular}{|c|c|}
\hline & A B S T R A C T \\
\hline & \multirow{4}{*}{$\begin{array}{l}\text { The present study was carried out to identify the chemical components in } \\
\text { Methanolic and Chloroform crude extracts of groundnut seed coat by Gas } \\
\text { Chromatography - Mass Spectrophotometry. The samples were extracted } \\
\text { ultrasonically followed by shaking at room temperature and kept overnight } \\
\text { at room temperature for cold extraction. Totally } 10 \text { compounds in } \\
\text { methanolic extract and } 14 \text { compounds in chloroform extract were } \\
\text { identified. The major compounds identified in methanolic extract of } \\
\text { groundnut seed coat were } 1,3,5 \text {, Benzenetriol, Cis - vaccenic acid 9,12- } \\
\text { Octadecadienoic acid and the compounds such as catechol, Phenol, } 4- \\
\text { butoxy, 1,3-Benzenediol, 4-propyl and oleic acid were identified in } \\
\text { chloroform extract. }\end{array}$} \\
\hline $\begin{array}{l}\text { Groundnut seed } \\
\text { coat, GC - MS } \\
\text { Analysis, } \\
\text { Chemical } \\
\text { components. }\end{array}$ & \\
\hline Article Info & \\
\hline $\begin{array}{l}\text { Accepted: } \\
\text { 23 May } 2017 \\
\text { Available Online: } \\
\text { 10 June } 2017\end{array}$ & \\
\hline
\end{tabular}

\section{Introduction}

India is the second largest producer of groundnut and its oil after china. It accounts for around $25 \%$ of the total oilseed production of the country. Groundnuts in India are mainly utilized for oil extraction followed by the production of peanut butter, roasted and salted Snacks. Nuts play a key role in the diets of human beings throughout the world. Nut by-products are generated during production and consumption and basically recognized as less market value residues. Before consumption, the groundnut seed coat was removed and regarded as waste. Over 0.74 million metric tons of groundnut seed coats are produced annually worldwide as a by-product of the groundnut processing industry (Sobolev and Cole, 2003). Many seed coats from various crops have been reported to possess plenty of phenolic compounds. Additionally these seed coats are an inexpensive source of nutraceuticals and functional ingredients (Kamath et al., 2007and Chikane et al., 2010). Groundnuts are rich source of natural procyanidins, the groundnut processing by products especially the groundnut seed coat contains a high concentration of phenolic compounds (Nepote et al., 2002; Nepote et al., 2004). Groundnut seed coats have an abundant amount of natural antioxidants and a high content of 
dietary fiber. It is a rich source of polyphenols including procyanidins and is shown to have hypolipidemic properties (Kubicka and Troszczynska, 2003 and Rishipal et al., 2014). Three classes of compounds such as phenolic acids, flavonoids and stilbene (resveratrol) are found in groundnut seed coat extracts (Yu et al., 2005). Despite being an abundant source of these health-promoting compounds, as not been exploited as a valuable natural resource. Extraction processes have been used to extract phenolic compounds from the under-utilized wastes, which can be used as nutraceuticals and functional ingredients in food industry (Wardhani et al., 2010). Solvents such as methanol, ethanol, butanol, acetone, chloroform and water have been commonly used for extraction of phenolics from plants (Lopez et al., 2011). Identifying valuable compounds in groundnut seed coat results in complete utilization and provides possible way to use as a natural alternative to synthetic preservatives in food processing.

\section{Materials and Methods}

\section{Collection of groundnut seed coat and preparation of extract}

Groundnut seed coat is one of the major byproduct in groundnut chikkis industries in Tamil Nadu. It was collected from laxmi villas chikkis processing unit located in oomachikulam of Madurai district, Tamil Nadu.

The collected sample was converted into powder and $10 \mathrm{~g}$ of sample was extracted with $100 \mathrm{ml}$ of HPLC grade methanol and chloroform in ultrasonic bath for $30 \mathrm{~min}$ at $27^{\circ} \mathrm{C}$ followed by continuous shaking in shaker for 6 hours at 300 RPM in room temperature and then the extract was filtered through $0.22 \mu \mathrm{m}$ membrane filter and directly injected into GC-MS system.

\section{Analytical conditions for GC-MS}

GC-MS analysis was carried out in a Shimadzu QP 2020 GC - MS System, fitted with Rxi - 5 Sil MS fused silica column cross bonded with 1, 4 - bis (dimethylsiloxy) phenylene dimethyl polysiloxane. The column length is 30 meters, inner diameter was 0.25 $\mathrm{mm}$ and film thickness is $0.25 \mu \mathrm{m}$. The maximum temperature limit for column was $320{ }^{\circ} \mathrm{C}$. Ultra-high purity helium $(99.99 \%)$ was used as carrier gas at a constant flow rate of $1.0 \mathrm{~mL} / \mathrm{min}$. The injection, transfer line and ion source temperatures were $260^{\circ} \mathrm{C}, 290$ ${ }^{\circ} \mathrm{C}$ and $230{ }^{\circ} \mathrm{C}$. The ionizing energy was 70 $\mathrm{eV}$. Electron multiplier voltage was obtained from auto tune. The oven temperature was programmed from $60{ }^{\circ} \mathrm{C}$ (hold for $2 \mathrm{~min}$ ) to $290{ }^{\circ} \mathrm{C}$ at a rate of $5{ }^{\circ} \mathrm{C} / \mathrm{min} . \quad 1.0 \mu \mathrm{L}$ of sample was injected into the system in split mode and the split ratio of 30: 1. All data were obtained by collecting the full-scan mass spectra within the scan range 45-550 amu. The identification and characterization of chemical compounds in various crude extracts was based on GC retention time. The obtained mass spectra were computer matched with those of standards available in NIST mass spectrum libraries.

\section{Result and Discussion}

In the present study the chemical components in methanolic and chloroform extracts in groundnut seed coat were analyzed by GCMS. The results revealed that there are ten compounds were identified in methanolic extract of groundnut seed coat. It contains the bio active compounds such as hexanal, it has strong antimicrobial activity against various food borne pathogens and more frequently used in shelf life improvement and preservation of processed foods, 1, 3, 5 Benzenetriol was used in treatment of various gastrointestinal disorders, 2,4-Decadienal is an aromatic substance found in various 
processed foods especially groundnuts and gives deep fat flavour, 9,12-Octadecadienoic acid is an omega 6 and essential fatty acid and $\mathrm{Cis}$ - vaccenic acid is an omega-7 fatty acid and it has anti - carcinogenic properties (Fig. 1 and Table 1).

In chloroform extract the compounds such as catechol, Phenol, 4-butoxy, 1,3, 5-
Benzenetriol and many fatty acid components such as n-Hexadecanoic acid, 9,12octadecadienoic acid, oleic acid, 6Octadecenoic acid is a monounsaturated omega-12fatty acid, fumaric acid, 4-octyl and Eicosanoic acid, octadecyl ester were identified (Fig. 2 and Table 2).

Table.1 Compounds identified in methanolic extract of groundnut seed coat by GC-MS

\begin{tabular}{|l|l|l|l|l|}
\hline S.No & $\begin{array}{c}\text { Retention } \\
\text { Time }\end{array}$ & \multicolumn{1}{|c|}{ Compound Name } & Area & Area \% \\
\hline 1. & 4.346 & Hexanal & 47747 & 3.36 \\
\hline 2. & 15.682 & Benzofuran, 2,3-dihydro & 94726 & 6.67 \\
\hline 3. & 15.802 & 5-Hydroxymethyl furfural & 85123 & 5.99 \\
\hline 4. & 18.725 & 2,4-Decadienal & 29716 & 2.09 \\
\hline 5. & 25.756 & 1,3,5- Benzenetriol & 287349 & 20.23 \\
\hline 6. & 30.854 & 2-Hydroxy-5-methylisophthalaldehye & 133921 & 9.43 \\
\hline 7. & 34.319 & n-Hexadecanoic acid & 282846 & 19.91 \\
\hline 8. & 37.727 & $9,12-$ Octadecadienoic acid & 142065 & 10.00 \\
\hline 9. & 37.854 & Cis - vaccenic acid & 238654 & 16.80 \\
\hline 10. & 45.148 & Cyclononasiloxane,octadecamethyl & 78412 & 5.52 \\
\hline
\end{tabular}

Table.2 Compounds identified in chloroform extract of groundnut seed coat by GC-MS

\begin{tabular}{|l|l|l|l|l|}
\hline S.No & $\begin{array}{c}\text { Retention } \\
\text { Time }\end{array}$ & \multicolumn{1}{|c|}{ Compound Name } & Area & Area \% \\
\hline 1. & 14.608 & Catechol & 184124 & 3.84 \\
\hline 2. & 14.635 & Phenol, 4-butoxy & 109008 & 2.27 \\
\hline 3. & 24.820 & 1,3,5-Benzenetriol & 433823 & 9.04 \\
\hline 4. & 25.089 & 1,3-Benzenediol, 4-propyl & 255793 & 5.33 \\
\hline 5. & 29.596 & 2-Hydroxcy-5-methylisophthalaldehate & 212818 & 4.43 \\
\hline 6. & 32.908 & n-Hexadecanoic acid & 491650 & 10.24 \\
\hline 7. & 36.140 & 9,12-Octadecadienoic acid & 219505 & 4.57 \\
\hline 8. & 36.260 & Oleic Acid & 644570 & 13.43 \\
\hline 9. & 36.360 & 6-Octadecenoic acid & 102676 & 2.14 \\
\hline 10. & 41.744 & Bis(2-(Dimethamino)ethyl) ether & 80824 & 1.68 \\
\hline 11. & 41.982 & 9-Octadecenoic acid & 127949 & 2.67 \\
\hline 12. & 45.675 & Decanedioic acid, dimethyl ester & 142699 & 2.97 \\
\hline 13. & 45.780 & Fumaric acid, 4-octyl & 147153 & 3.03 \\
\hline 14. & 45.840 & Eicosanoic acid, octadecyl ester & 222887 & 4.64 \\
\hline
\end{tabular}


Fig.1 Chromatogram of methanolic extract of groundnut seed coat

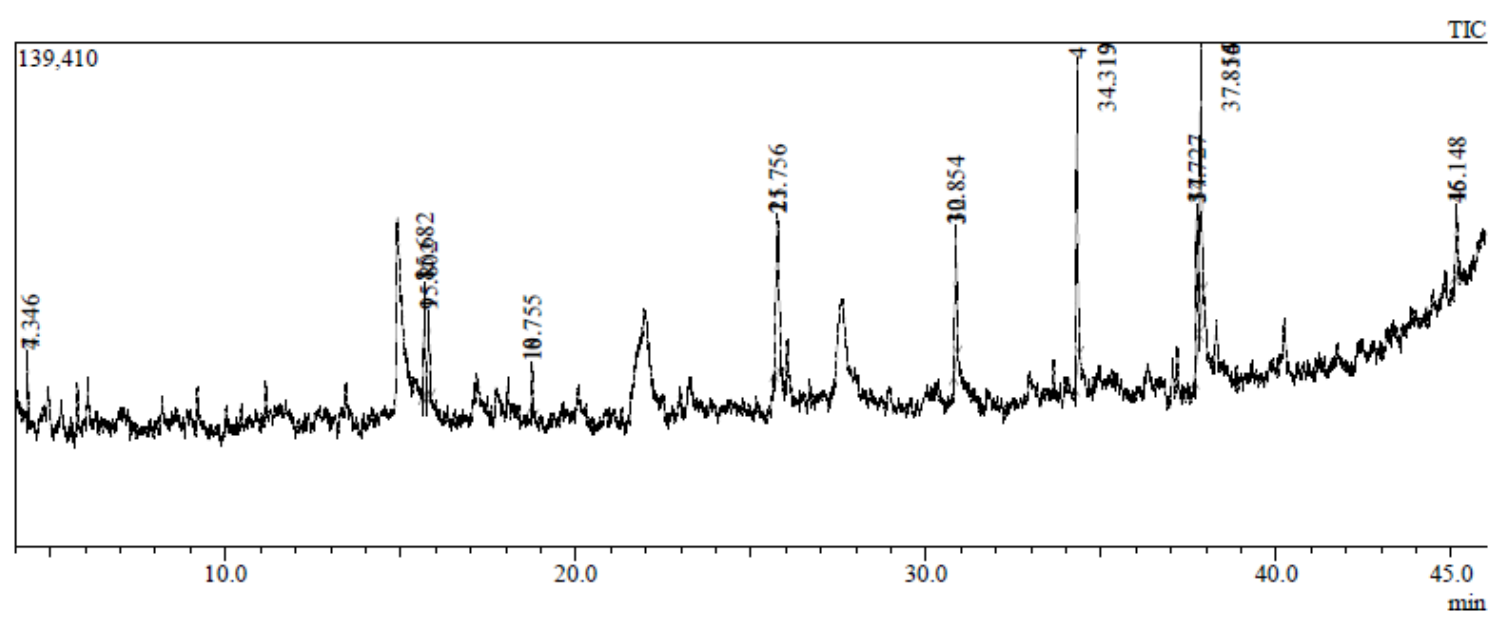

Fig.2 Chromatogram of chloroform extract of groundnut seed coat

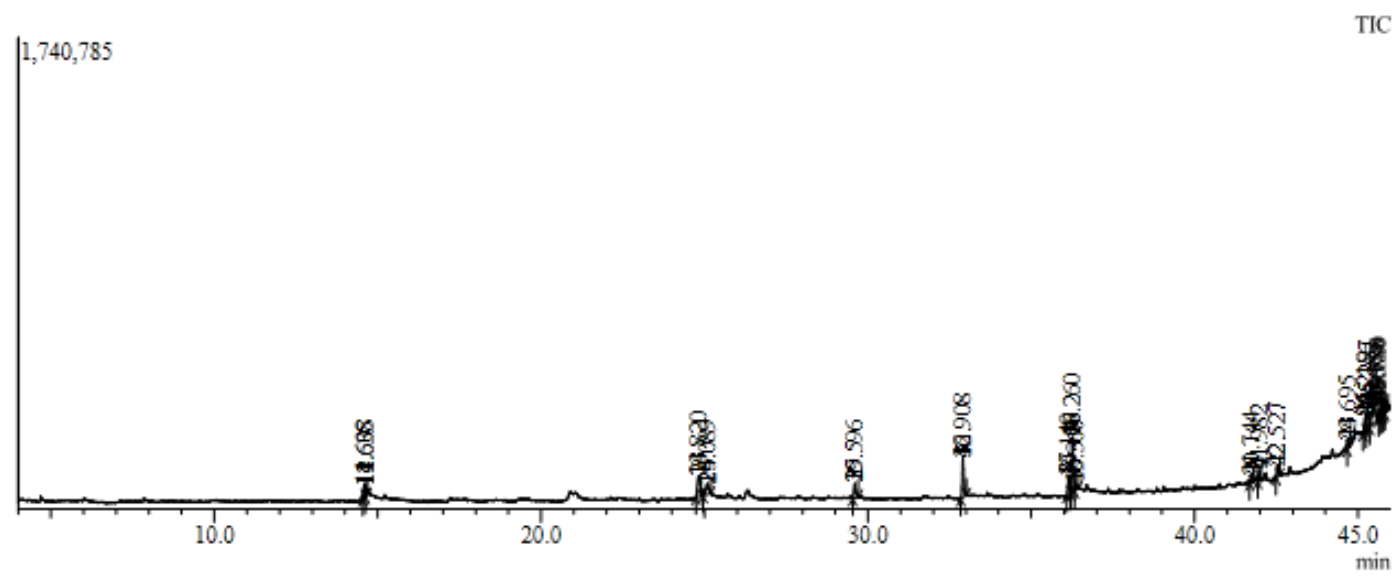

In conclusion, plants contains variety of phytochemical components, many of them are biologically active compounds and known to have pharmacological activities ( $\mathrm{Gu}$ et al., 2014). The bioactive secondary metabolites have been shown to reduce the risk and progression of diseases such as cancer, cardiovascular, neurodegenerative diseases, etc. by scavenging free radicals through various biological mechanisms (Ansari and Khodagholi, 2013). The results of GC-MS indicated that groundnut seed coat contained numerous bioactive components belongs to various classes such as Polyphenols, alkaloids, flavonoids, steroids and it has some fatty acids that will provide health benefits. The groundnut seed coat contains various antioxidants. So, the more efficient utilization of groundnut seed coat benefit industry and health of the people and the utilization of groundnut seed coat as a renewable raw material for antioxidant compounds will provide protection and enhancement against various life style diseases, while it can also be used as an inexpensive source of polyphenols in foods and dietary supplements.

\section{Acknowledgement}

The authors would like to thank Dr.N.Senthil, Ph.D, Project Director, Center of Innovation and Professor and Head, Department of Biotechnology and Mr. S. Vellai Kumar, Assistant Professor, Department of Biotechnology, Agricultural College and Research Institute, Tamil Nadu Agricultural 
University, Madurai for providing infrastructure and necessary research facilities to conduct GC-MS analysis.

\section{References}

Ansari, M. and Khodagholi, F.2013. Natural products as promising drug candidates for the treatment of Alzheimer's disease: molecular mechanism aspect. Curr Neuropharmacol;11(4): 414-429.

Chikane, M. R., Parwate, D. V. and Ingle, V. N. 2010. In Vitro study of antibacterial activity of g-irradiated and irradiated leguminous seed coats, Int. J. Pharm. Biol. Arch., 1, 335.

Gu, R., Wang, Y., Long, B., Kennelly, E., $\mathrm{Wu}$, S.and Liu,B. 2014. Prospecting for bioactive constituents from traditional medicinal plants through ethno botanical approaches. Biol Pharm Bull:37(6): 903-915.

Kamath, V. and Rajini,P. S. 2007. The efficacy of cashew nut (Anacardium occidentale L.) skin extract as a free radical scavenger, Food Chem., 103, 428.

Kubicka, E. and Troszczynska,A. 2003. Antioxidative potential of lentil seed coat towards lipoxygenase activity and b-carotene oxidation, Pol. J. Food Nutr. Sci., 12, 147.

Lopez, A., Rico, M., Rivero, A. and De Tangil,M. S. 2011. The effects of solvents on the phenolic contents and antioxidant activity of Stypocaulon scoparium algae extracts, Food Chemistry, 125-1104.

Nepote, V., Grosso, N.R.and Guzman,C.A.2002. Extraction of antioxidant components from peanut skins. Grasas Y Aceites 54:391-395.

Nepote, V., Mestrallet, M.G., and Grosso,N.R. 2004. Natural antioxidant effect from peanut skins in honeyroasted peanuts. Journal of Food Science. 69: 295-300.

Rishipal, R., Bansode, Priscilla Randolph, Mohamed Ahmedna, Steven Hurley, Tracy Hanner, Sarah, A., Schwatrz Baxter, Thomas, A., Johnston, Mingming Su, Bryce, M., Holmes, Jianmei Yu. and Leonard L. Williams. 2014. Bioavailability of polyphenols from peanut skin extract associated with plasma lipid lowering function. Food Chemistry (148) 24-29.

Sobolev, V.S., Cole, R.J. 2003.Note on utilization of peanut seed coat. J. Sci Food Agric 84:105-111.

Wardhani, D. H., Vazquez, J. A. and Pandiella,S. S. 2010. Optimisation of antioxidants extraction from soybeans fermented by Aspergillus oryzae, Food Chemistry, 118-731.

Yu, J., Ahmedna, M. and Goktepe, I. 2005. Effects of processing methods and extraction solvents on concentration and antioxidant activity of peanut skin phenolics. Food Chemistry, 90(1-2), 199-206.

\section{How to cite this article:}

Sivananth, C., S. Amutha, G. Hemalatha, M.L. Mini and Karthikeyan, G. 2017. Identification of Various Chemical Compounds in Methanolic and Chloroform Crude Extracts of Groundnut Seed Coat by GC-MS. Int.J.Curr.Microbiol.App.Sci. 6(6): 1952-1956.

doi: https://doi.org/10.20546/ijcmas.2017.606.228 